\title{
ORDENS DE INDEXICALIDADE MOBILIZADAS NAS PERFORMANCES DISCURSIVAS DE UM GAROTO DE PROGRAMA: SER NEGRO E HOMOERÓTICO
}

\author{
Glenda Cristina Valim de Melo* \\ Universidade de Franca \\ Franca, São Paulo, Brasil \\ Luiz Paulo da Moita Lopes** \\ Universidade Federal do Rio de Janeiro \\ Rio de Janeiro, Rio de Janeiro, Brasil
}

\begin{abstract}
Resumo: Neste artigo, analisamos as ordens de indexicalidade mobilizadas nas performances discursivas de raça, gênero e sexualidade de Hiago, um garoto de programa. Para tal, nos ancoramos nas Teorias Queer e em teorizações sobre a web como um espaço de coexistência de discursos e atores. Esta pesquisa é de cunho etnográfico virtual (HINE, 2000 e 2005) e os dados foram gerados em um chat entre um dos pesquisadores e Hiago. Como instrumental analítico, embasamo-nos nas propostas de Goffman ([1979]1998) de alinhamento e enquadre e na perspectiva de ordem de indexicalidade Blommaert (2006 e 2010). Observamos que foram mobilizadas algumas ordens de indexicalidade contraditórias nas múltiplas performances discursivas de Hiago.
\end{abstract}

Palavras-chave: Raça. Ordens de indexicalidade. Performances discursivas. Teorias queer. Web.

\section{INTRODUÇÃO}

No senso comum, nas diásporas africanas no Brasil e em outras partes do mundo (como nos Estados Unidos), ser negro ainda é sinônimo de heteronormatividade e virilidade; se, porventura, ainda no senso comum, homens negros não encenarem tais performances discursivas e corporais, podem ser acusados de estarem negando sua própria origem e contrariando as matrizes hegemônicas desta raça. Sendo assim, embasados em Hutchinson (1999) e Sullivan (2003), podemos dizer que há uma normalização entre raça negra, sexualidade e gênero ou uma percepção homofóbica de

\footnotetext{
* Sou grata ao CNPq pela bolsa 159621/2010-0, no âmbito do Edital MEC/CAPES e MCT/CNPq/FINEP No 28/2010 - Programa Nacional de Pós-Doutorado - PNPD 2010, que possibilitou este estudo. Tal bolsa foi concedida ao Projeto "Letramentos Digitais Singularidades do Ethos, Performances e Narrativas Identitárias", do Prof. Dr. Luiz Paulo da Moita Lopes (CNPq 560303/2010-06). Email: glendamelo09@gmail.com.

** Agradeço ao CNPq pela Bolsa de Produtividade que propiciou esta pesquisa (CNPq 3033-1/2009-0), assim como ao auxílio à pesquisa da FAPERJ (E -26/110.065/2012) e ao PNPD (MEC/CAPES e $\mathrm{MCT} / \mathrm{CNPq} / \mathrm{FINEP}$ ) referido na nota anterior. Sou também grato ao CNPq pelo auxílio (470547/20120), concedido pelo Edital Universal (14-2012). Email: moitalopes@pq.cnpq.br.
} 
muitos negros e não negros quanto ao tema, visto que nas palavras do primeiro autor, a homoafetividade, no senso comum, seria um produto da chamada cultura branca e colidiria com a agenda antirracista.

Para compreender as dicotomias que nascem com esta perspectiva, neste estudo investigamos um chat com Hiago Waldeck, um homem negro, gay e garoto de programa, que é autor do blog "Um Diário Escrito por Hiago Waldeck"”. Nele, analisamos as ordens de indexicalidade (BLOMMAERT, 2010) mobilizadas pelo participante em suas performances discursivas de raça, gênero e sexualidade. Salientamos que no blog citado, o participante problematiza e narra suas experiências como homem, negro, gay e garoto de programa, mas é no chat com um dos pesquisadores que ele detalha como compreende e inter-relaciona os preconceitos vivenciados por questões relativas à raça, gênero, sexualidade, classe social etc.

Ancorados nos preceitos da Modernidade Recente (RAMPTON, 2006) e na Linguística Aplicada Indisciplinar e Transgressiva (MOITA LOPES, 2006; PENNYCOOK, 2006), esta investigação pode contribuir para o fortalecimento dos estudos da área linguagem e raça no Brasil, bem como para ampliar a perspectiva da questão racial nos estudos queer, pois segundo McDonald (2006), nem sempre este traço performativo é considerado nas pesquisas da área (ver, porém, MELO; MOITA LOPES, 2013 e 2014). Sendo assim, para discutir todos estes aspectos, neste artigo, primeiramente, abordamos raça, sexualidade, gênero etc., orientados pelas teorias queer; em seguida, introduzimos as teorizações sobre a internet como espaço de coexistência de Discursos ${ }^{2}$ e atores. A seguir, expomos a metodologia de pesquisa, os construtos analíticos e, finalmente, passamos à análise.

\section{NEGROS E GAYS: RAÇA E SEXUALIDADE PELO VIÉS DAS TEORIAS QUEER}

Buscando desconstruir normalizações que causam sofrimento, ancoramo-nos nas Teorias Queer ${ }^{3}$ para desnaturalizar os traços performativos abordados nesta investigação, a saber: raça, gênero, sexualidade etc. Segundo Louro (2004), tais teorias são contrárias a qualquer forma de sedimentação da vida social, independente de onde vier, e almejam ainda contestar as verdades, as subjetividades etc. que foram emolduradas como hegemônicas pela Modernidade.

As Teorias Queer entendem que o sujeito social é constituído pela linguagem, pela História e também por meio da intersecção de vários traços performativos como raça, gênero, classe social, escolaridade e outros. Nesta perspectiva, de acordo com Sullivan (2003) e Barnard (2004), a raça seria sexualizada e a sexualidade seria

\footnotetext{
${ }^{1} \mathrm{O}$ participante autorizou por escrito a análise de seu blog, de suas narrativas e do seu Facebook, desde que fossem reconhecidas as fontes e o nome do blog fosse mantido no original.

${ }^{2}$ Seguimos aqui a perspectiva de Gee $(2004$, p.15) de que discurso com letra minúscula se refere à linguagem em uso, enquanto que Discurso, com letra maiúscula, está relacionado às ideologias, às formas de estar no mundo e a conhecimentos.

${ }^{3}$ Os pressupostos das Teorias Queer são discutidos, por exemplo, em Sedgwick ([1990] 2008), Sullivan (2003), Barnard (2004) e Louro (2004).
} 
racializada ou, como indica Sedgwick ([1990]2008, p. 31): algumas dimensões de sexualidade não estariam relacionadas apenas ao gênero, mas também à classe social e à raça.

A linguagem aqui é relevante, porque é entendida como performativa e é, portanto, por meio dela que somos construídos como homens, negros, homoafetivos etc. Compreendemos, então, a linguagem como ação ou em performance que ocorre no momento da enunciação (AUSTIN, [1962]1990; DERRIDA, [1972] 1988); como performance (ação), a linguagem constrói e é constitutiva do sujeito social. Os atos de fala como performativos produzem efeitos semânticos que nos fazem homens, negros etc. Eles são incessantemente repetidos pelos atores com os quais convivemos e pela escola, igreja, família, mídia e outras instituições. Pela iterabilidade, tais efeitos são compreendidos como essência e, como tais, são entendidos como preexistindo ao discurso, sendo então cristalizados nos corpos (BUTLER, 2004). Assim, se tornam materialidade em nós e por nós, pelo outro e pela linguagem.

Partindo da proposta de Butler ([1999] 2003, 2004) para explicar a constituição de gênero, é possível dizer que raça e outros traços performativos obedecem ao mesmo processo. A construção sócio-histórica desses traços é tão naturalizada e assimilada que se torna uma substância. Essa substância ou essência nos faz acreditar que a própria materialidade dos corpos não seria por si uma construção. Nossos corpos negros ou brancos são efeitos semânticos ou resultado das repetições de vários atos de fala performativos naturalizados de raça, gênero, sexualidade e outros que ouvimos ao longo de nossa existência (SOMMERVILLE, 2000; SULLIVAN, 2003; BARNARD, 2004 e WILCHINS, 2004). Isso não quer dizer, por outro lado, que tais atos não possam ser desnaturalizados dando margem a outros significados sobre quem podemos ser, possibilitando nossa reinvenção.

Considerando a intersecção entre raça negra, sexualidade, gênero etc., de acordo com Sullivan (2003) e Silva Júnior (2011), este último autor especificamente em relação aos discursos que permeiam a sociedade brasileira, deparamo-nos com uma normalização em particular: os homens negros, ao se declararem gays estariam ferindo os princípios dessa raça. Para entendermos melhor este pressuposto, retomamos dois grandes Discursos do senso comum sobre a sexualidade desses atores: o primeiro se refere ao seu pênis avantajado, desempenho sexual animalesco e avaliado como negativo; e o segundo também foca a genitália grande, mas com o desempenho sexual estigmatizado como fenomenal e positivo (SILVA JÚNIOR, 2011).

O primeiro Discurso constitui o corpo do homem negro, sua sexualidade e sensualidade por atos de fala performativos negativos. Henrique (2007, p. 2) indica tal posicionamento quando menciona a perspectiva darwinista, que descreve os negros como "criaturas forjadas no clima quente, que exaltam as 'paixões' e os desejos desenfreados responsáveis pela degradação social". Atribuições semelhantes são descritas também por Munanga (1986, p.16) que, ao criticar os discursos da Ciência da Raça, menciona que "sexualidade, nudez [...] constituem tema-chave da descrição do negro na literatura científica [de uma época]”. Nessa literatura, segundo Sullivan (2003, p.60), "o pênis grande conota grande permissividade". Sendo assim, o negro dotado de 
pênis grande, além de inferior, ainda seria permissivo e teria sua sexualidade desvalorizada.

Já o segundo Discurso, foco de nosso interesse, é bastante identificável, na contemporaneidade, nos atos de fala performativos da chamada negritude masculina. $\mathrm{O}$ pênis grande é objeto de desejo de homens e mulheres, já que no imaginário do senso comum os homens negros teriam um desempenho sexual considerado acima da média. Nas palavras de Silva Júnior (2011, p. 53), a "identidade sexual do homem negro é exaltada pelo modelo hegemônico, como reprodutor, viril, bem dotado". Ainda de acordo com o autor, que se apoia em Frosh, Phoenix e Pattman (2002), a sexualidade do homem negro estaria localizada na estrutura falocêntrica, o que o posicionaria como superior aos homens de outras raças do ponto de vista sexual.

De acordo com Lima e Cerqueira (2007, p. 7), podemos hipotetizar que tais performances discursivas de valorização do homem negro como viril e grande conquistador de parcerias sexuais seriam influenciadas pelos efeitos semânticos de atos de fala de negritude. Segundo os autores, a negritude "se constitui através da normalização do negro heterossexual, representado pela emblemática virilidade de sua força física, agressividade, violência, grande apetite sexual e pênis potente". Ainda com base nesses autores, esse negro seria "inabalável, [e] protegeria a si mesmo e aos subalternos mais frágeis (mulheres e crianças) contra a opressão racial" (LIMA; CERQUEIRA, 2007, p. 7). No senso comum, poderíamos relacionar o segundo Discurso com aquele sobre o chamado negão. Segundo Simões et al. (2010, p. 53-54), os negões "tendem a ser alvo de grande interesse erótico e podem ser tomados por garotos de programa. Manifestam-se também [...] expectativas relacionadas a tamanho de pênis, potência e desempenho sexual acima da média".

Contudo, esses atos de fala performativos cristalizam a raça, o gênero e a sexualidade dos homens negros em dois binarismos: no passado, a sexualidade considerada animalesca e negativa, e no presente, a sexualidade elogiada que despertaria as fantasias de muitos(as). Tais atos de fala, assim, deslegitimam as subjetividades dos corpos ébanos, naturalizam normalizações trazidas por estes dois Discursos hegemônicos que caracterizam a sexualidade desse homem como "anormal"4 (FOUCAULT, [2001] 2010). Além disso, ambos os Discursos tratam tanto raça, gênero e sexualidade como traços predeterminados e preexistentes à linguagem.

Já em relação à homoafetividade de homens negros, conforme Lima e Cerqueira (2007, p.7) apontam, o negro homoafetivo "é tido como portador de um distúrbio moral, da alma ou da natureza [...]. É incapacitado para salvar a raça, tanto quanto é incapaz de proteger os mais fracos”. Para estes antropólogos e ainda segundo Sullivan (2003) eles, em comparação aos heteronormativos, são vistos como fracos e traidores da raça negra, sendo tal perspectiva compartilhada por membros da comunidade negra e branca heteronormativa. Como apontado por Hutchinson (1999, p.30) a conduta homoafetiva do negro seria compreendida como "anormal, indesejada e não-negra".

\footnotetext{
4 Embasados em Foucault (2001/2010), compreendemos anormal aqui como aquele que deve ser corrigido e curado; o estranho, o monstro, o degenerado, o perigoso, o diferente.
} 
Esse gay negro não seria acolhido na comunidade gay padrão e branca, visto que nela há também uma negação de sua participação nos espaços de confraternização e de poder (HUTCHINSON, 1999; LIMA; CERQUEIRA, 2007). De acordo com Lima e Cerqueira (2007, p. 7), há "uma afirmação da identidade [homoafetiva] que passa necessariamente pelas perspectivas definidas por um mercado de consumo voltado para o público [homoafetivo] urbano, branco, jovem e integrado às relações de produção".

Consequentemente, para ser aceito nesta comunidade, muitos negros gays precisariam ter poder aquisitivo, status e prestígio. Contudo, os aspectos sociais e econômicos de muitos homens negros em contexto brasileiro, retratados pelos censos do $\mathrm{IBGE}^{5}$, além do próprio racismo e da homofobia citados por Hutchinson (1999), poderiam colocar estes corpos em situação de apagamento e/ou de negação de sua sexualidade. Assim, mais do que os brancos, eles teriam de encenar performances heteronormativas para serem aceitos, incluídos e reconhecidos, como mencionado anteriormente.

Quando um gay negro 'sai do armário', ele desconstrói as cristalizações trazidas pela raça negra sobre sexualidade e gênero. Podemos dizer embasados em HUTCHINSON (1999), que isto possibilita também a compreensão de que tais traços estão interligados e também em constante tensão. $\mathrm{O}$ autor ainda acrescenta que um negro constituído, em nossas palavras, por traços performativos de raça, sexualidade, gênero etc. "pode lidar com uma compreensão de raça mais complexa e multidimensional" (p. 30). Sendo assim, uma intersecção entre os traços performativos citados que privilegia uma única possibilidade de agir é reducionista, além de sedimentar e normalizar a heteronormatividade, as masculinidades hegemônicas ${ }^{6}$ e uma visão de raça negra consciente ${ }^{7}$. São apagadas, desta forma, as infinitas outras probabilidades de construção, constituição de gênero, raça negra e sexualidade para estes atores, ocasionando, assim, um aprisionamento desses sujeitos sociais, mas sem as correntes da senzala. Tal ponto, conforme Sommerville (2000), Sullivan (2003), Barnard (2004) e Wilchins (2004) indicam, nos impediria de termos uma visão mais completa dos variados sujeitos sociais. Ademais, de acordo com Sedgwick ([1990] 2008, p. 10), "uma compreensão desconstrutiva destes binarismos torna possível identificá-los como lugares peculiares e densamente carregados por manipulações poderosas e potenciais...”.

Desta forma, estas matrizes hegemônicas são limitadoras, castradoras e causam sofrimentos aos que tentam se enquadrar nelas por uma cobrança social. São atos de violência aos próprios homens negros. Como aborda Butler (1998, p. 39), que critica a noção de sexo, mas considerando aqui a intersecção de raça negra, gênero e sexualidade, é possível dizer que:

\footnotetext{
${ }^{5}$ Para mais informações sobre os censos brasileiros, acessar $<$ http://www.ibge.gov.br $>$.

${ }^{6}$ Conferir Badinter (1993), Connel (1995, 2000) e Moita Lopes (2002) para definições de masculinidades hegemônicas.

${ }^{7}$ Em Melo; Moita Lopes (2013), em pesquisa sobre as performances discursivas de mulheres negras, os resultados indicam que há uma diferença entre negro consciente (defensor da ancestralidade africana negra) e não consciente (não defensor dos princípios africanos de negritude).
} 
o sexo [a raça e o gênero] não [descrevem] uma materialidade prévia, mas [produzem e regulam] a inteligibilidade da materialidade dos corpos. ... [as categorias sexo, raça e gênero impõem] uma dualidade e uma uniformidade sobre os corpos a fim de manter a sexualidade reprodutiva como uma ordem compulsória. Discuti em outro lugar com mais precisão como isso funciona, mas para nossos propósitos aqui, gostaria de sugerir que esse tipo de classificação pode ser chamado de violento, forçado e que essa ordenação e produção discursiva dos corpos de acordo com [as categorias sexo, raça, gênero] é em si mesma uma violência material.

Desconstruir os binarismos criados pela intersecção de raça, sexualidade e gênero, com base nas teorizações queer (SEDGWICK, [1990] 2008; SOMMERVILLE, 2000; SULLIVAN, 2003; BARNARD, 2004; MOITA LOPES, 2004; WILCHINS, 2004) torna-se relevante, porque a raça negra mesclada à sexualidade, ao gênero, à bi/hetero/homo/transafetividade pode indicar diversas possibilidades de performances discursivas quanto à sexualidade, à própria raça e ao gênero. As cristalizações impedem que os homens negros hetero/homo/bi/transafetivos etc. "[aprendam] a se construir discursivamente em termos de desejo sexual de modos diferentes por toda a vida" (MOITA LOPES, 2004, p. 4), já que "há muitas dimensões da sexualidade" (SEDGWICK, [1990] 2008, p. 35).

Na Modernidade Recente, estamos envolvidos em uma grande reflexividade sobre nós mesmos (GIDDENS, 1991), o que possibilita nosso propósito político na pesquisa de nos voltarmos para aqueles cujos corpos foram apagados na Modernidade. Sendo assim, pensamos que homens, negros, homo/bi/transafetivos etc. podem reverter tal violência, transgredir e reinventar suas performances discursivas. Por um lado, pela internet é possível potencializar estas ações, visto que elas nos propiciam maior reflexividade e/ou diferentes possibilidades de acesso performativo que contribuem para que os sujeitos sociais desnaturalizem e desconstruam discursos hegemônicos. Por outro lado, a rede pode ser também o espaço de consumo de corpos e de ratificação dessa sexualidade exacerbada de homens negros, como veremos a seguir.

\section{A WEB COMO ESPAÇO HÍBRIDO}

As Tecnologias de Informação e Comunicação (TICs) têm possibilitado uma infinidade de usos para os mais diferentes tipos de usuários. Segundo Jenkins (2008), nesta sociedade convergente surgem distintas novas formas de interação. Por meio de ferramentas tecnológicas cada dia mais móveis e híbridas (computadores, celulares, tablets etc.) há um ambiente propício para que os diversos atores sociais se reinventem e façam o mesmo com suas atividades cotidianas, criando, por exemplo, mundos online que proporcionam vivências variadas antes inimagináveis.

Desta forma, a web é um lugar do híbrido e de coexistências de discursos e atores sociais. Sendo assim, no ambiente online, homens, negros de sexualidades diversas, poderiam encontrar menos dificuldade em discutir sobre raças, gêneros etc., visto que nesse espaço eles estariam protegidos pela amplitude, anonimato e as múltiplas possibilidades oferecidas pela rede (PARREIRAS, 2009). Por meio de blogs, redes sociais etc., torna-se possível contar outras histórias, desconstruir as dicotomias, sem o 
receio da depreciação ou hostilidade do face a face. Concomitantemente, a rede é um ambiente em que esses mesmos corpos ébanos podem ser erotizados, expostos, desejados, consumidos e podendo o próprio corpo ser ressignificado pela figura, por exemplo, de avatares (PARREIRAS, 2009).

Considerando Bauman (2008), que aborda a questão do consumo, constatamos que homens negros, como mercadorias sexuais, também são expostos em sites, blogs, comunidades de afinidades e grupos. Os homens negros nus na web seriam, portanto, um tipo específico de mercadoria, aquelas voltadas a realizar os prazeres sexuais e as fantasias de parceiros(as) que buscam o chamado desempenho sexual acima da média. Nestas condições, é possível dizer que na web estes corpos negros erotizados e suas subjetividades estariam a serviço do exacerbado capitalismo contemporâneo também no mundo online, pelo toque na tela.

Uma rápida busca no Google ilustra esta questão. Ao digitarmos homens negros, o resultado foi de 4.890 .000 sites a eles associados, sendo que apenas na primeira página tais negros eram indexicalizados por itens lexicais como lindos, sexy, bonitos, calientes etc. Filtrando um pouco mais a busca para homens negros gays, tivemos 5.530 .000 sites sobre este tema. Já na primeira página encontramos links para blogs, sites, vídeos, imagens que expõem os corpos ébanos como em uma vitrine.

Nesta perspectiva, o centro da discussão é ocupado por usuários diversos. Esses atores, por sua vez, deixariam de ser apenas consumidores para, segundo Arriazú et al. (2008, p. 201), se tornarem prosumidores ${ }^{8}$, como ocorre com o participante desta pesquisa ao contar na rede parte de sua rotina como garoto de programa, negro e gay, fazer seu marketing pessoal ao relatar como foi um dia de seu trabalho ${ }^{9}$, erotizar seu corpo, denunciar preconceitos diversos etc.

Sendo assim, a web se tornou lugar onde é possível tanto reinventar a vida social (MOITA LOPES, 2010) como consumir corpos, daqueles outrora apagados pela Modernidade como negros, gays, lésbicas, pessoas trans etc. Ela é, portanto, um espaço de coexistência de Discursos, contradições e resistências, cujos propósitos e sujeitos sociais são variados. A internet é também um espaço "de experimentar alternativas e de pensar novos futuros ou, minimamente, de deixar escapar ou afugentar os fantasmas escondidos no armário" (MOITA LOPES, 2013, p. 129). É neste contexto de Discursos em competição que se situa Hiago Waldeck, participante desta pesquisa.

\section{CONTEXTO, METODOLOGIA DE PESQUISA E CONSTRUTOS ANALÍTICOS}

Seguindo a perspectiva de Hine (2000 e 2005) e Rutter e Smith (2005), este estudo é de cunho etnográfico virtual. Nele partimos, primeiramente, de uma exploração

\footnotetext{
${ }^{8}$ Junção do vocábulo produtor e consumidor que "sintetizam o usuário imaginário da web 2.0" (ARRIAZÚ et al. 2008, p. 201).

${ }^{9}$ Apesar de o blog e de o Facebook de Hiago Waldeck não serem foco desta investigação, eles foram analisados por um dos pesquisadores. Neste espaço, o blogueiro usa recursos multimodais (por exemplo vídeo) tanto para narrar sua história como para enfatizar o seu marketing pessoal como garoto de programa.
} 
por seis meses do blog 'Um Diário Escrito por Hiago Waldeck!', criado em fevereiro de 2012 por Hiago Waldeck, nome usado pelo blogueiro em seu trabalho como garoto de programa. Considerando o último acesso em 13 de agosto de 2013, o corpus é constituído por mais de 500 textos, divididos entre narrativas do participante, seus posts, comentários seus e de seguidores.

Nesta exploração etnográfica, notamos que Hiago é seguido por pessoas de várias partes do mundo. Algumas narrativas produzidas pelo autor são publicadas também no Facebook, mas o inverso não ocorre. Entre as várias histórias muitas nos chamaram atenção, mas nosso corpus de análise para este estudo é o texto intitulado "Preconceitos, Racismo e Outros", postado no blog em 28 de março de 2012, às 9h10. Ele nos orientou durante o chat entre um dos pesquisadores e Hiago, por interseccionar preconceito racial, sexual, classe social e religião - um aspecto que nos interessa pela natureza queer de tal performance.

Partindo dessa narrativa, conduzimos uma entrevista online que usamos como instrumento de geração de dados, no Facebook com o blogueiro, em 26 de abril de 2013, das $13 \mathrm{~h} 54$ às $16 \mathrm{~h} 12$, visando saber como os Discursos de raça, sexualidade, gênero e outros são entextualizados, transpostos, recontextualizado ${ }^{10}$, interseccionados, encenados e indexicalizado nas performances discursivas de Hiago. Os participantes desta conversa são um dos pesquisadores e Hiago Waldeck. Embasamo-nos, nesta investigação, na perspectiva de Blommaert e Dong (2006, p. 39) ${ }^{11}$ de que a entrevista é uma conversa colaborativa. Sendo assim, consideramos aqui o chat como uma entrevista, um tipo particular de conversa ou prática discursiva, estruturada por perguntas e/ou temas que se gostaria de discutir; portanto, como em uma conversa, a entrevista online também deve fluir.

Nesta investigação, o construto teórico analítico de indexicalidade é relevante, porque indica como nossas performances discursivas locais na enunciação sinalizam Discursos construídos social, histórica e coletivamente que permeiam o mundo social (OCHS, 1992; BLOMMAERT, 2006) ou, nas palavras de Rocha (2013, p.127), o fenômeno da indexicalidade nos indicaria que "não há cisão entre escalas micro [discurso] e macrossociais [Discursos], principalmente porque essa classificação por vezes se dá a partir de convenções estabelecidas na teoria social”. Esta indexicalização de sentidos de escalas macro em escalas micro ocorre via recursos semióticos diversos (índices linguísticos, como discutidos a seguir) mobilizam valores indexicais que se "orientam de acordo com ordens de indexicalidade" (BLOMMAERT, 2010; FABRÍCIO, 2013). Para Blommaert (2010), que se embasa em Silverstein (2003), a

\footnotetext{
${ }^{10}$ Segundo Rampton (2006, p. 118), a entextualização é a formulação de uma experiência em palavras e proposições; já a transposição é o mover de um texto por meio de entextualização para outra situação; enquanto a recontextualização são os novos sentidos atribuídos ao texto no processo de transposição, ou seja, em seu novo contexto.

${ }^{11}$ Apesar de os autores abordarem a entrevista em contexto presencial, compreendemos que ela traz contribuições para o mundo online.

${ }^{12}$ Blommaert (2006 e 2010) se ancora na proposta de ordem do discurso foucaultiana para desenvolver esta conceituação. Aqui a ordem do discurso é compreendida como procedimentos impostos ou por qualquer sociedade ou pelo próprio discurso que controlam as produções discursivas, ora fazendo emergir alguns discursos, ora outros.
} 
indexicalidade é ordenada em dois modos: o primeiro deles, pela ordem indexical, um construto que nos permite entender como os sujeitos sociais em suas performances narrativas indexicalizam ideologias e/ou Discursos das grandes narrativas que orientam nossas vidas sociais. Em outras palavras, a ordem indexical é produtiva, porque constrói categorias no mundo social que podem se cristalizar no decorrer do tempo e da história, criando, assim, modos essencializados e específicos para certos sujeitos e grupos sociais. Considerando a ordem indexical raça/sexualidade do homem negro, observamos que no mundo social, há crenças e expectativas de performances discursivas (padrões convencionalizados) sobre a hipersexualização e as práticas heteronormativas específicas para os corpos ébanos, construídas ao longo da história e por longo tempo.

Já o segundo modo é verificado pela ordem de indexicalidade que de acordo com Blommaert (2010) são os valores, as crenças ou normas que são hierarquizados, estratificados e apontados no processo de indexicalização de Discursos (BLOMMAERT, 2010), por meio de escalas locais e translocais. Segundo ele, a escala, termo emprestado da História e da Geografia, é uma metáfora para imaginar "o movimento de mensagens ou pessoas pelo espaço e pelo tempo que são constituídos por normas, expectativas e códigos" (p. 32). Os eventos ou fenômenos sociais, segundo o sociolínguista, ocorrem simultaneamente no espaço e no tempo, sendo indissociáveis e contextualizados socialmente; uma escala em nível pessoal (local) pode ser situada em uma escala impessoal ou genérica (translocal), por exemplo, e nesta situação é relevante considerar a questão de espaço e tempo, a hierarquização, a estratificação e a relação de poder instauradas entre elas, visto que escalas diferenciadas apontam para níveis distintos de normalização entre os sentidos (de/co)notacionais. Aqui, optamos por analisar as ordens de indexicalidade, porque elas nos sinalizam as hierarquizações de certos valores para determinados corpos em um espaço de tempo determinado, ou seja, elas apontam para os valores, os possíveis efeitos, as estratificações destes valores nas performances discursivas de Hiago.

Já para a análise das performances discursivas de raça, gênero e sexualidade, fazemos uso dos construtos de alinhamento e enquadre propostos por Goffman ([1979], $1998)^{13}$. O enquadre, neste estudo, é entendido como explicando a atividade que estaria sendo realizada e os sentidos dados pelos falantes ao que dizem. Footing, segundo Goffman ([1979]1998, p. 70), "representa o alinhamento, a postura, a posição, a projeção do eu de um participante na sua relação com o outro, consigo próprio e com o discurso que está em construção".

Respaldar-nos-emos nos índices linguísticos (SILVERSTEIN, 1985), entendidos como marcas linguísticas que sinalizam as ações semióticas dos participantes na interação. Em outras palavras, observaremos os traços linguísticos que possibilitam estudar os enquadres, os alinhamentos, as ordens de indexicalidade mobilizados na interação. Enfatizamos, contudo, que estes elementos linguísticos estão condicionados a forma como os participantes incitam sentidos com base em convenções linguísticas

\footnotetext{
${ }^{13}$ Apesar de tais pressupostos teóricos não terem sido propostos para a interação online, acreditamos que possam auxiliar na compreensão da vida virtual.
} 
(TANNEN, [1984] 2005). Para esta análise, focalizaremos, especificamente, os dêiticos, as modalizações, as predicações e as referências ${ }^{14}$.

Os dêiticos, segundo Ilari e Geraldi (2006, p. 66), são "palavras que mostram" e podem viabilizar a comunicação; são caracterizados, conforme Levinson (2007), por pronomes pessoais de primeira e segunda pessoas, os demonstrativos, tempos verbais, advérbios de tempo e lugar e uma série de traços linguísticos relacionados à enunciação. Já as modalizações, propostas por Bronckart ([1999] 2007), são classificadas em quatro grupos. As lógicas são compreendidas como os julgamentos sobre o valor da verdade das proposições enunciadas. Já as deônticas avaliam o que é enunciado à luz dos valores sociais, ou seja, os eventos sociais são apresentados como socialmente permitidos, proibidos, necessários, desejáveis etc. Quanto às apreciativas, qualificam os julgamentos mais subjetivos como bons, maus, estranhos etc. Finalmente, as pragmáticas introduzem um julgamento sobre uma das facetas de responsabilidade de um ator em relação ao processo em que é agente, como o querer fazer e o dever fazer.

Diferentemente de uma conversa face a face, na interação do chat do Facebook, no momento da conversa, ambos estavam em espaço e localidade diferentes. Os dados estão armazenados nessa rede social, no recurso mensagem dos participantes, e podem ser recuperados a qualquer momento. Ademais, há possibilidade de toda a conversa ser relida antes de um próximo comentário por ambos os participantes e de eles interagirem com outros durante a entrevista.

\section{RAÇA, GÊNERO, SEXUALIDADE E CLASSE SOCIAL NO CHAT COM HIAGO WALDECK}

Salientamos brevemente que antes da interação a seguir, há um ritual de apresentação, indexicalizado pelos índices linguísticos (boa tarde, tudo bem?, tudo bem com você?). Percebemos um enquadre de apresentação laminado por enquadres de elogios, assim, como por alinhamentos de cordialidade e de expectativas entre os participantes. Após todo o ritual da apresentação e elogios, os participantes passam a abordar a narrativa do participante intitulada "Preconceitos, Racismo e Outros". No excerto 1, na página seguinte, observamos uma alteração no enquadre de apresentação, para o de uma conversa sobre uma das narrativas do blog, mostrada nas linhas 22 e 23.

No excerto1, após a mútua apresentação mencionada brevemente, a pesquisadora se realinha ao participante de forma interessada, questionando-o sobre a narrativa "Preconceito, Racismo e Outros", postada no blog em 28 de março de 2012, às 9h 10min. Na história em questão, o blogueiro relata os preconceitos racial, financeiro e religioso que enfrenta; além disso, ele se posiciona contra qualquer um deles. Neste alinhamento, Hiago detalha, reflexivamente, o contexto de produção da narrativa mencionada como mostram as linhas de 25 a 28.

O blogueiro se alinha ainda em solidariedade a um personagem da narrativa ( $u m$ amigo), ausente na conversa e que sofreu preconceito, conforme as linhas 25 a 27 . Ao

\footnotetext{
${ }^{14}$ Neste artigo, a referência é compreendida como elementos do mundo ao quais os participantes se referem, enquanto que a predicação são as caracterizações desses elementos (WORTHAM, 2001).
} 
fazê-lo, Hiago relata suas próprias experiências ao justificar a razão de ter produzido a narrativa em questão. Identificamos, também, que ele mobiliza sentidos de valor da ordem de indexicalidade relativa a preconceitos, posicionando-se contrários a eles (linhas 25-27): nesse dia em que escrevi o post, um amigo meu tinha acabado de sofrer preconceito, eu na minha forma de tentar o correto resolvi postar sobre coisas que aconteceram comigo na tentativa de eu mesmo enxergar o mundo.

\section{Excerto 1: Conversa sobre a Narrativa do Blog}

22. Hiago Waldeck Qual seria a história?

23. Glenda Melo Eu gostei de todas elas, mas quero analisar esta aqui: PRECONCEITO,

24. RACISMO E OUTROS. o que você acha desse seu texto?

25. Hiago Waldeck Nesse dia em que escrevi o post, um amigo meu tinha acabado de

26. sofrer preconceito, eu na minha forma de tentar ser correto, resolvi postar sobre

27. coisas que aconteceram comigo na tentativa de eu mesmo enxergar o mundo. Na

28. minha cidade, muitas pessoas gostam de se julgar as melhores por simplesmente ter

29. sido casadas com pessoas de situação financeiras boas.

30. Glenda Melo sei

31. Hiago Waldeck Muitas delas gostam e fazem questão de jogar na cara dos outros que

32. são melhores. Pior de tudo, são quando vejo pessoas negras tendo preconceito com

33. pessoas da própria raça.

34. Glenda Melo com certeza, isto você acha que isto ocorre muito?

35. Hiago Waldeck Com certeza. A sensação de poder que isso dá, faz com que as pessoas

36. continuem sendo e agindo dessa forma. Não deveria, mas muitos se sentem bem ao

37. agir assim. Um prazer que não sei de onde vem, mas que os deixa com muita

38. autoestima

Portanto, durante todo o excerto percebemos que ambos os participantes projetam alinhamentos de concordância, interesse, cumplicidade, sugeridos pelas modalizações lógicas (com certeza, linha 34; e, com certeza, linha 35) e também de curiosidade em relação ao outro, sinalizado pela pergunta (Qual seria a história? O que você acha desse seu texto?).

Nas linhas 26 e 27, notamos que Hiago se coloca como conhecedor de que há outras leituras possíveis sobre os preconceitos sofridos pelo amigo, mas enfatiza apenas a sua leitura, sugerida pelos dêiticos (eu, oculto ou não; comigo, minha forma). Observamos ainda que o participante encena performances discursivas como alguém crítico e reflexivo sobre as relações de poder exercidas pela ascensão econômica, linhas 35 a 38, sinalizadas pela predicação (a sensação de poder), pelas referências (um prazer, muita autoestima) e ainda por meio dos verbos no presente do indicativo(sentem, faz, dá, continuem sendo e agindo, deixa, vem), sugerindo ações habituais de atores sociais com os quais o blogueiro poderia conviver.

Ademais, Hiago traz à tona um suposto preconceito entre negros(as), linhas $32 \mathrm{e}$ 33, mobilizando os valores da ordem de indexicalidade preconceito racial entre negros sugerida por meio de predicação e referência (pessoas negras; preconceito com pessoas da própria raça) e pela modalização apreciativa (pior de tudo, são quando vejo pessoas negras tendo preconceito com pessoas da própria raça), indicando uma avaliação e uma crítica do blogueiro à questão. A ordem de indexicalidade que valora negativamente o preconceito racial entre negros parece orientar as performances discursivas do participante como homem negro não ativista, já que os militantes não compreenderiam tal situação desta forma. 
Em relação à indexicalidade, ao serem acionados os sentidos da ordem de indexicalidade de preconceito racial entre negros, observamos uma hierarquização, ou seja, ter preconceito é compreendido como negativo, mas o preconceito entre negros é avaliado como pior pelo blogueiro (pior de tudo, são quando vejo pessoas negras tendo preconceito com pessoas da própria raça). Esta ordem de indexicalidade orienta as performances discursivas de Hiago ao longo do excerto 1 que são: de um homem negro que sofreu preconceitos raciais e de classe social, crítico e reflexivo sobre acontecimentos ao seu redor e perceptivo das relações de poder.

No excerto 2, os participantes tematizam a ascensão socioeconômica de Hiago. Ao longo do excerto citado, no enquadre geral de conversa sobre a narrativa "Preconceito, Racismo e Outros", percebemos que os participantes projetam alinhamentos de concordância e cumplicidade, sinalizados, por exemplo, pelos índices linguísticos entendi e ah entendi:

\section{Excerto 2: Conversa sobre Preconceitos Raciais e Ascensão Socioeconômica}

39. Glenda Melo Eu vi vários blogs em que os homens negros apareciam nus e havia

40. sempre o foco no bem dotado. Me explica uma coisa, as pessoas passaram a te

41. discriminar menos, porque você é conhecido ou por que você se veste diferente ou

42. por que você tem uma situação financeira melhor ou tudo isto junto? Rs

43. Hiago Waldeck Tudo isso junto. Depois que comecei a me vestir melhor, tive milhares

44. de elogios, isso ajudou para que o povo me tratasse melhor, ainda mais vendo minhas

45. roupas de marca. $O$ fato de ser conhecido, ajudou sim, mas apenas na parte que

46. realmente interessa a eles, a parte financeira. Depois que muitos começaram a ver

47. que eu ganhava dinheiro com isso, tive a admiração deles

48. Glenda Melo entendi...

49. Hiago Waldeck todos vinham falar comigo, para no dia seguinte me pedir mil reais

50. emprestado pra pagar conta.

51. Glenda Melo ah entendi, você acha que a questão do dinheiro te deixou menos negro

52. aos olhos dos outros?

53. Hiago Waldeck Com certeza! O fato deles saberem que eu posso gastar e fazer tudo o

54. que um branco rico faz, acabou me deixando uma pessoa branca aos olhos deles.

55. Glenda Melo entendi...

Observamos que a pesquisadora traz por meio de um comentário e uma pergunta a questão da classe social para a conversa mesclando-a à raça, ao gênero e à sexualidade (me explica uma coisa, as pessoas passaram a te discriminar menos, porque você é conhecido ou por que você se veste diferente ou por que você tem uma situação financeira ou tudo isto junto?). Por sua vez, Hiago encena performance identitária de que é constituído por todos os traços performativos citados pela pesquisadora, sugerida pelos dêiticos pronominais tudo, isso e pelo índice linguístico junto sugerindo a intersecção dos traços mencionados.

Quando questionado pela pesquisadora se a ascensão econômica havia deixado Hiago menos negro aos olhos de outros, já que o participante cita em vários momentos de seu blog que a sua ascensão financeira modificou as performances discursivas de outros em relação a ele, o blogueiro se alinha em concordância e ratifica sua pergunta com uma modalização lógica, acompanhada de um ponto de exclamação (Com 
certeza!), ratificando seu embranquecimento, por assim dizer ${ }^{15}$. Identificamos, ainda, que o aspecto financeiro associado à raça poderia amenizar o preconceito em relação ao segundo traço performativo. Além disto, parece-nos que mobilizar os valores da ordem de indexicalidade relativos à ascensão econômica como forma de reconhecimento amenizaria os valores da ordem de indexicalidade relativa a preconceito racial. Tais valores são sinalizados pela modalização deôntica ( $O$ fato deles saberem que eu posso gastar e fazer tudo), pela referência (branco e uma pessoa) e predicação (rico e branca), sugerindo que o blogueiro, devido à sua nova situação financeira, tem socialmente condições de consumir como um sujeito social branco.

Nas linhas 39 a 55, Hiago mobiliza a ordem de indexicalidade ascensão socioeconômica como forma de reconhecimento, sinalizada pela assertiva(Depois que comecei a me vestir melhor, tive milhares de elogios), pelos dêiticos pronominais e de tempo (isso, me, minha, deles, eu, depois, todos), o condicionamento trazido pelo subjuntivo (tratasse e tive), pela predicação e referência (melhor e roupas de marca), a frase adversativa (mas apenas na parte que realmente interessa a eles, a parte financeira) e a sentença causal (todos vinham falar comigo, para no dia seguinte me pedir mil reais emprestado pra pagar conta). Esses índices linguísticos indexicalizam a ascensão financeira do participante. Ao situá-la em escala pessoal, ele relata os efeitos semânticos de tal mudança em sua vida e a relação dela com o preconceito racial.

Nas linhas 51 a 54, observamos que o participante volta a associar o seu poder de consumo ao de uma pessoa branca. Esta questão é sinalizada pelos índices linguísticos que sinalizam performances de classe social associadas à branquitude (eu posso gastar, fazer tudo que um branco rico faz, uma pessoa branca aos olhos deles). Isto pode nos indicar que, para ascender socioeconomicamente em contexto brasileiro, seria necessário encenar performances identitárias de sujeitos sociais brancos, visto que eles teriam um maior poder aquisitivo e de consumo do que os atores negros, como indicado, por exemplo, pelos censos do IBGE, já citado.

Neste excerto, notamos que as performances Identitárias encenadas porHiago são de um homem negro que ascendeu financeiramente devido ao trabalho como garoto de programa, cujo poder aquisitivo lhe permite comprar itens outrora impossíveis, mas ele está também ciente dos efeitos desta mudança na forma como é tratado. Como no excerto 1, o blogueiro encena também performances discursivas críticas, reflexivas sobre o preconceito racial e a questão financeira. Tais performances são orientadas pela ordem de indexicalidade referente à ascensão socioeconômica como forma de reconhecimento e pelos valores sobre ser negro e ser branco.

\footnotetext{
${ }^{15}$ Ainda que a pesquisadora possa ser entendida como tendo induzido Hiago à resposta, é notável a firmeza com a qual logo a seguir ele se alinha à pesquisadora. Acrescente-se a isso o alto grau de reflexividade da parte de Hiago sobre a vida social que nos surpreendeu a todo momento da etnografia virtual, realizada durante seis meses. Os vários textos do blog (que pode ser facilmente acessado pelo leitor em http://odiariosecretto.blogspot.com.br/?zx=4ec1dd19a3f864f9) indexicalizam tal reflexividade, como por exemplo o próprio texto que motivou esta entrevista intitulada "Preconceitos, Racismo e Outros", no qual ele indexicaliza Discursos sobre raça e classe social. Além disso, a entrevista analisada aqui tem o objetivo de estudar os sentidos indexicalizados na prática discursiva que a entrevista instaura. Em outras práticas discursivas, Hiago pode performatizar outros sentidos.
} 
Dando prosseguimento ao enquadre de conversa sobre a narrativa, observamos que os participantes projetam alinhamentos de concordância, compreensão, cumplicidade, críticos e reflexivos entre eles, também encontrados na seção anterior. No excerto 3, os participantes abordam os preconceitos sofridos por Hiago:

\section{Excerto 3: Conversa sobre (Des)vantagem de Ser Negro}

56. Glenda Melo Você diz no seu texto que já sofreu preconceito, em que momento ser

57. negro te ajuda e em que momento te atrapalha?

58. Hiago Waldeck Na realidade, o único momento em que minha cor me ajudou, foi na

59. hora em que resolvi me divulgar como garoto de programa. Negros acabam fazendo

60. parte da fantasia de muita gente e isso foi um ponto positivo a meu favor. Agora o

61. lado que atrapalha é:

62. Glenda Melo sei

63. Hiago Waldeck Entrar numa loja e todos os seguranças te seguirem achando que vai

64. roubar algo, ou quem sabe dar uma parada em uma esquina, e logo te revistarem

65. achando que está com drogas.

66. Glenda Melo entendi... isto acontece muito mesmo, comigo também.

67. Hiago Waldeck Pior de tudo, é quando senta ao lado de alguém e a pessoa cisma de

68. trocar a bolsa de lado, achando que irá pegá-la e sair correndo

69. Glenda Melo verdade... e como... e quando seguram a bolsa...

70. Hiago Waldeck Antigamente eu andava muito simples, nada de luxo enchia meus

71. olhos, até que um dia fui seguido numa loja, só porque estava de simples. Sei disso,

72. pois meu amigo trabalhava na loja e comentou comigo depois.

73. Glenda Melo Nossa, você ainda vive muito estas experiências? Você disse que o negro

74. acaba fazendo parte da fantasia de muita gente, pode me dar mais detalhes?

75. Hiago Waldeck Hoje em dia, não. Acabei ficando conhecido e muitos daqueles que

76. tinham preconceito comigo, acabaram sendo pessoas "amigas", mas só por causa do

77. personagem que eu me tomei. Tudo na base do interesse. Mas as vezes me vem um

78. cliente e que está a fim de atacar, aí as ofensas são grande quando me chamam de

79. negro ou preto.

80. Hiago Waldeck A parte sobre fantasia: A fama dos negros é uma: ser bem dotado.

81. Basta dizer que é negro e logo de cara imagina alguém com um pênis de $25 \mathrm{~cm}$, isso

82. instiga muita gente que gosta de situações em que o homem tem seu membro

83. avantajado. Por isso, muita gente tem a fantasia com negros.

84. Glenda Melo entendi.

85. Hiago Waldeck Este sim, chega a ser o lado bom de ser negro.

No excerto acima, encontramos o primeiro enquadre laminado, conversa sobre (des)vantagem de ser negro, que é indicado pelo questionamento da pesquisadora por meio de uma pergunta (em que momento ser negro te ajuda e em que momento te atrapalha?). Hiago, por sua vez, projeta um alinhamento de reflexão ao abordar a questão, sinalizado, por exemplo, pelo índice linguístico na realidade. Observamos ainda que há alinhamentos explícitos de mútua compreensão entre a pesquisadora e o participante, sinalizados pelo verbo no pretérito perfeito do indicativo, reticências (entendi...), pela assertiva generalista (isto acontece muito mesmo) e pela assertiva particular (comigo também), mostrando que ela experiência o mesmo. Além disso, identificamos que há um alinhamento de ratificação entre os dois participantes do chat.

Neste enquadre, linhas 63 a 72, o participante apresenta algumas ações preconceituosas vivenciadas por ele e por outros(as) negros(as). Elas são sugeridas por verbos no infinitivo, indicativo e subjuntivo (entrar numa loja, seguirem, vai roubar, dar, revistarem, está, senta, cisma, trocar, irá pegá-la), sugerindo ações preconceituosas experimentadas continua, cotidiana e hipoteticamente. Estes índices linguísticos valoramos sentidos da ordem de indexicalidade relativa aos preconceitos 
raciais sofridos por negros, mobilizados por Hiago. A ordem de indexicalidade em questão sinaliza os exemplos de preconceito racial, mencionados pelo blogueiro.

Identificamos também que o participante, mesmo ascendendo socioeconomicamente, ainda sofre preconceito racial como indicado pelo operador discursivo adversativo (Mas), pelo dêitico de frequência (às vezes me vem um cliente e que está a fim de ataca) e pela modalização apreciativa, indicando um julgamento negativo da subjetividade (ai as ofensas são grandes quando me chamam de negro ou preto).

Já em relação à vantagem de ser negro, o participante aborda a fantasia despertada pelo corpo ébano, linhas de 80 a 85, enfatizando novamente o estereótipo de um tipo de negro (LIMA; CERQUEIRA, 2007; SIMÕES et al., 2010; SILVA JÚNIOR, 2011), discutido anteriormente, também presente nos discursos hegemônicos do senso comum. A predicação e as referências mencionadas anteriormente (a fama dos negros, bem dotado, pênis de $25 \mathrm{~cm}$, membro avantajados) indicam que são mobilizados valores da ordem de indexicalidade relativa à sexualidade dos homens negros. Ao fazê-lo, o blogueiro os situa em suas performances discursivas de garoto de programa negro e homoafetivo em escala pessoal.

De um lado, o Hiago entextualiza, transpõe atos de fala performativos de valorização da sexualidade do homem negro e os recontextualiza em enunciados sobre negros, gays e garotos de programa, desnormalizando, portanto, os sentidos de virilidade e grande apetite sexual (LIMA; CERQUEIRA, 2007) como exclusivos de um grupo de negros, compreendidos como heteronormativos. Por outro lado, ele ratifica a sexualidade predeterminada da raça negra como um todo, uma visão essencialista, hierarquizando positivamente valores da ordem de indexicalidade relativa à hipersexualização da raça negra.

Outro ponto que merece ser citado é que o participante reforça esses atos de fala performativos de fantasia e os usa em seu trabalho como garoto de programa, sugerindo, assim, que a internet também é um espaço para consumo de corpos ébanos e subjetividades (BAUMAN, 2008).Os atos de fala são ratificados no trecho a seguir, mencionado quase ao final da entrevista, pela referência produto e pela interrogação pra que rosto sendo que é o corpo que irá usar, sugerindo o consumo de seu corpo:

[...] eu antigamente quando tinha outro blog...[...] Com o tempo resolvi mostrar apenas o "produto", como eu mesmo digo a eles: "pra que rosto sendo que é o corpo que irá usar" (Hiago, 2013). ${ }^{16}$

Percebemos ainda que, ao recontextualizar os valores da matriz de sexualidade exacerbada do homem negro, o blogueiro desconstrói o Discurso de sexualidade do homem negro gay como negativo, desestabilizando, assim, os valores tradicionais de ordens de indexicalidade sobre sexualidade e raça. O participante parece se apropriar de tais atos de fala performativos para seu marketing pessoal de modo a ratificar as

\footnotetext{
${ }^{16}$ Trecho citado no momento da entrevista em que o blogueiro menciona a importância de seu blog. 
performances discursivas do personagem que ele se tornou (mas só por causa do personagem que eu me tornei).

Contudo, estas normalizações podem gerar sofrimentos aos homens negros hetero/bi/homo/transafetivos, pois apagam outras possibilidades de encenar sua sexualidade (SEDGWICK, [1990] 2008), aprisionando-os em Discursos cristalizados sobre o desejo sexual (MOITA LOPES, 2004).

Já no excerto 4, a pesquisadora projeta o segundo enquadre, a conversa sobre o assumir-se gay, sinalizado pela pergunta (Hiago, me explica como foi pra você negro se assumir como gay?), linha 86. Os participantes, aqui, se alinham como em uma conversa informal e íntima:

\section{Excerto 4: Conversa sobre o Sair do Armário de Hiago}

86. Glenda Melo entendi. Hiago me explica como foi pra você negro se assumir como gay?

87. Hiago Waldeck o começo foi difícil ter que ouvir racistas me chamando de bicha preta.

88. Era algo que no começo magoava muito, a ponto de eu querer largar tudo e tentar ser

89. feliz com mulher.

90. Glenda Melo sei.

91. Hiago Waldeck Minha familia não teve muito receio com isso, estavam tão|

92. preocupados em me chamar de vagabundo do que discutir minha sexualidade

93. Glenda Melo sei.

94. Hiago Waldeck Sem contar que muitos acham vergonhoso o fato de um negro se

95. assumir gay! Acham que devíamos estar ocupando lugares inferiores e não nos

96. expondo dessa forma, achando que estamos fazendo papel de ridículo.

97. Glenda Melo vc sentiu que ser negro e gay era algo inaceitável ou não percebeu isto

98. ou percebeu de outra forma?

99. Hiago Waldek Sim, em certo ponto da minha vida eu me achava um monstro por ser 100 .assim

101.Glenda Melo por ser assim como, não entendi

102 Hiago Waldeck Assim negro e também gay. Depois de tantas pessoas dizendo na

103 minha cabeça ser algo errado e ruim, comecei a acreditar no que me diziam. Eu já

104.cheguei a ter preconceito quando era criança. Não me aceitava gay e menos ainda

105 negro tanto que sol era algo que evitava, só pra ter que ficar com a pele bem clara.

106. Glenda Melo sei. entendi.

107 Hiago Waldeck Algumas vezes acabava sendo atacado quando alguém dizia que

108 queria ter a minha cor, e na resposta eu dizia que queria ser branco

109. Glenda Melo entendi

110 Hiago Waldeck Hoje em dia, me orgulho de ser assim. Conheceu muita gente na

111 mesma situação que eu?

112.Glenda Melo rs... e me diz uma coisa, vc acha que na vida de um modo geral, as

113. experiências de ser negro, de ser gay e de ter uma condição financeira melhor são

114 misturadas ou você separa que sofreu $x$ por ser gay, y por ser negro, d, por não ter $\$$ ?

115 .Ou você vê isto de outra forma... Conheço muitos negros que sofreram preconceitos,

116 muitos... todos os que conheço...e que na hora em que ganham $\$$, as pessoas mudam

117.o tratamento. Mas não conheci nenhum negro e oficialmente gay. $\mathrm{O}$ que toma suas

118 histórias inéditas e importantes.

119 Hiago Waldeck No meu modo de pensar, não separo as situações. Pra mim ser negro

120 dıtıcultou arrumar servıço, ser pobre tambem e ser gay, nem se tale.

121. Glenda Melo entendi..

122 Hiago Waldeck hoje em dia alguns lugares estão mudando, tanto que já vejo gays bem

123.afeminados trabalhando em comércio, coisa que antigamente não se via.

124. Glenda Melo sei.

125 Hiago Waldeck Mas isso acontece quando o dono do estabelecimento chega a ser da

126 mesma opção sexual

127. Glenda Melo entendi. Você conhece muitos gays negros?

128 Hiago Waldeck Poucos. Aqui na minha cidade não são muitos.

129. Glenda Melo conheço poucos, raros na verdade e acho que há muito sofrimento em

130 não se assumir como gay... para o cara negro, porque há toda expectativa que ele seja

131.um pegador hetero

O blogueiro, neste excerto, aborda os sofrimentos causados pelo seu sair do armário como negro, indexicalizados por referência e predicação (bicha preta, vergonhoso, monstro, papel de ridículo); verbos no pretérito imperfeito do indicativo, 
sinalizando mágoas que persistem (era e magoava),o advérbio de intensidade, sugerindo a profundidade da ação (muito), pela modalização apreciativa, avaliando o sair do armário(o começo foi difícil); e pela modalização deôntica, exprimindo um desejo do blogueiro (a ponto de eu querer largar tudo e tentar ser feliz com mulher). Hiago, ao expor os sofrimentos vivenciados como negro e homoafetivo também hierarquiza negativamente os valores acerca da ordem de indexicalidade referente à homoafetividade do homem negro.

Nas linhas de 94 a 100, o participante entextualiza, transpõe e recontextualiza Discursos hegemônicos do senso comum sobre negros e gays, sinalizados por meio de predicação (vergonhoso);pela assertiva (sem contar que muitos acham vergonhoso o fato de um negro se assumir gay);pela modalização lógica (Sim), indicando que o conteúdo a seguir deve ser compreendido como verdade; e pela modalização apreciativa (eu me achava um monstro por ser), qualificando sua subjetividade negativamente como homem, negro e gay.

Como em Melo e Moita Lopes (2014), cuja pesquisa relata as performances narrativas de uma blogueira que se descobriu negra após os 20 anos, ele destaca a sua dificuldade em se aceitar negro e gay, linhas de 103 a 108, sinalizada pela predicação (errado e ruim); pelo dêitico temporal (Depois); pela locução verbal no pretérito perfeito do indicativo (comecei a acreditar), sugerindo uma ação passada e acabada para Hiago; e pelo pretérito imperfeito do indicativo (no que me diziam), sinalizando uma ação inacabada por parte dos outros; pelo dêitico temporal e verbo no pretérito perfeito do indicativo, indicando os preconceitos do blogueiro em um momento específico de sua vida(Eu já cheguei a ter preconceito quando era criança); pela modalização pragmática (Não me aceitava gay e menos ainda negro tanto que sol era algo que evitava, só pra ter que ficar com a pele bem clara), mostrando um julgamento do próprio Hiago, e pela modalização deôntica (Algumas vezes acabava sendo atacado quando alguém dizia que queria ter a minha cor, e na resposta eu dizia que queria ser branco), expressando um desejo do participante de ser branco.

Identificamos aqui uma hierarquização entre ser negro e ser gay, em que ser negro seria pior do que ser gay (Não me aceitava gay e menos ainda negro tanto que sol era algo que evitava, só pra ter que ficar com a pele bem clara). Essa negação de si mesmo indexicaliza o sofrimento da perspectiva reducionista e destrutiva de classificar o homem negro em termos de normalizações cristalizadas que encontramos na sociedade e os efeitos semânticos de discursos hegemônicos materializados nos corpos.

Os índices linguísticos, verbos no pretérito perfeito, imperfeito e futuro do pretérito do indicativo (comecei, cheguei, era, aceitava, evitava, dizia, acabava, queria) sinalizam que são situações passadas, já resolvidas no momento vivido por Hiago. Vale salientar que o dêitico temporal (Hoje em dia) e a assertiva (me orgulho de ser assim) indexicalizam que a não aceitação em ser negro e gay parece resolvida. Estes índices linguísticos mobilizam valores positivos da ordem de indexicalidade relativa à homoafetividade de Hiago como homem negro.

Por outro lado, ao mobilizar valores relativos à ordem de indexicalidade acerca da sexualidade do negro homoafetivo, vemos dois movimentos do participante: no primeiro, ele, gay e negro, se apropria dos atos de fala performativos dessa sexualidade; e no segundo, ele ratifica os atos de fala performativos de raça negra e sexualidade, acentuados como algo predeterminado para todos os membros da raça negra. Contudo, 
em ambos os movimentos, podemos notar a sedimentação de sexualidade e de raça como única, fixa e exacerbada para todos os atores sociais negros. O blogueiro, ao posicionar-se como negro, gay e cujo desempenho sexual é acima da média e superior ao de outras raças como garoto de programa e negro, está apto a realizar fantasias sexuais que estão no imaginário de outros homens, desconstruindo os atos performativos de valorização do negro apenas como heteronormativo.

Outro aspecto relevante a citar é que Hiago, durante o chat, intersecciona e desestabiliza, como em sua narrativa no blog, os traços performativos de raça, sexualidade, classe social e gênero em suas performances identitárias. Deste modo, podemos dizer que esta intersecção, segundo Sommerville (2000), Sullivan, (2003), Barnard (2004), nos possibilitaria compreender os sujeitos e as práticas sociais sob outra perspectiva, ou seja, de forma desnormalizadora ou queerizada.

Finalmente, nas diversas performances discursivas observadas, identificamos o blogueiro mobilizando e estratificando sentidos e valores de várias ordens de indexicalidade: o preconceito racial sofrido por negros, o preconceito entre negros, ascensão socioeconômica como forma de reconhecimento, sociabilidades da raça negra e da branca, sexualidade exacerbada do homem negro, a sexualidade do negro homoafetivo, a hipersexualidade da raça negra e a homoafetividade/sexualidade do homem negro. Ele se apropria de valores dessas ordens em escala genérica, por meio de Discursos e atos de fala performativos que permeiam a sociedade e os precipita em suas múltiplas performances identitárias locais, indicando-nos, assim, como elas constituem os diferentes modos de agir "do personagem que Hiago se tornou" e como neste contexto local de uma prática discursiva, o blogueiro compreende os discursos de raça, sexualidade, gênero, etc., trazendo também hibridez, instabilidade e contradição para os sentidos de raça, gênero, sexualidade e classe social.

\section{CONSIDERAÇÕES FINAIS}

Embasados nas Teorias Queer, podemos dizer que nas performances identitárias de Hiago, há contradições. Por um lado, o blogueiro desconstrói a qualificação do homoafetivo negro como fraco etc. Por outro lado, o participante ratifica que todos os sujeitos sociais negros teriam uma hipersexualidade, colocando-a como anteriores ao discurso, uma visão questionada pelas Teorias Queer segundo as quais somos constituídos na e pela linguagem em performance.

Além disso, as várias essencializações de raça negra, gênero e sexualidade heteronormativa são limitadoras e geram muito sofrimento e violência (BUTLER, 1998) para os sujeitos sociais, como experienciados por Hiago. Embasados em Hutchinson (1999), Sullivan (2003) e Lima e Cerqueira (2007), é possível dizer que elas posicionam negros homoafetivos como traidores da raça negra, cuja homoafetividade os excluiria da comunidade racial em questão.

Nesta pesquisa, as ordens de indexicalidade referentes à sexualidade e à raça são precipitadas nos Discursos do blogueiro de forma essencializada, apagando, assim, as diversas possibilidades de ser quanto à raça, sexualidade, classe social e gênero (SEDGWICK,1990/2008; SULLIVAN, 2003; BARNARD, 2004; MOITA LOPES, 2004). 
No entanto, a intersecção entre raça, sexualidade, gênero e classe social por parte de Hiago e as ordens de indexicalidade que mobiliza sugerem movimentos contraditórios e complexos das performances discursivas deste ator e os conflitos que as cercam. Tal aspecto pode nos indicar, na perspectiva de Hall (2006), que o blogueiro experimenta a fluidez e as contradições de nossos tempos. Portanto, ao essencializar suas performances discursivas de raça etc., Hiago simultaneamente se reinventa. A intersecção de traços performativos (raça, gênero, sexualidade e classe social) vai ao encontro das teorizações queer e das desnormalizações de vida social que tais teorias ensejam.

Este artigo, que espera contribuir para a construção de um campo de estudos na área de linguagem e raça no Brasil, alerta-nos para o fato de que a grande complexidade vivida nos contextos online possibilita compreendermos que podemos ser outros. No caso desta pesquisa, como homens negros homoafetivos podem performar e reinventar outras sexualidades, compreender e vivenciar outras formas de desejos sexuais (SEDGWICK, [1990] 2008; MOITA LOPES, 2004), de raça e de gênero.

\section{REFERÊNCIAS}

ARRIAZÚ, R.; BLANCO, R.; CARO, G.; ESTALELLA, A.; CRUZ, E. G. Intalados en la cresta de la web 2.0.? Cinco autores em busca de la 'big.two.dot.zero. In: SÁBADA, I.; GORDO, A. (Orgs.) Cultura digital y movimentos sociales. Madri: Catarata, 2008.

AUSTIN, J. L. Quando dizer é fazer. Palavras e ação. Trad. Danilo Marcondes. Porto Alegre: Artes Médicas, [1962] 1990.

BADINTER, E. Xy. Sobre a identidade masculina. Rio de Janeiro: Nova Fronteira, 1993.

BARNARD, I. Queer race: cultural interventions in the racial politics of queer theory. New York: Peter Lang, 2004.

BAUMAN, Z. Vida para consumo. Trad. de Carlos Alberto Medeiros. Rio de Janeiro: Jorge Zahar Ed., 2008.

BLOMMAERT, J; DONG, J. Etnographic field wolk: a beginner's guide. Bristol: Short Run Press, 2006. BLOMMAERT, J. Social linguistics scales. London: Working Papers Urban Language \& Literacies, 2006.

The sociolinguistics of globalization. Cambridge: Cambridge University Press, 2010.

BRONCKART, J. P. Atividade de linguagem, textos e discursos: por um interacionismo sociodiscursivo. Trad. Anna Raquel Machado e Péricles Cunha. 2. ed. São Paulo: EDUC, [1999] 2007.

BUTLER, J. Fundamentos contingentes: o feminismo e a questão do pós-modernismo. Cadernos Pagu 11, p.11-42, 1998.

Problemas de gênero: feminismo e subversão da identidade. Trad. Renato Aguiar. Rio de

Janeiro: Civilização Brasileira, [1999] 2003.

Performative acts and gender constitution: an essay in phenomenology and feminist theory. In:

BIAL, H. (Org). The performance studies reader. New York, 2004.

CONNELL, R. W. Políticas de masculinidade. Trad. Tomaz Tadeu da Silva. Educação e Realidade, v. 20, n. 2, p. 185-206, jul/dez. 1995.

The men and the boys. Berkeley: The University of California Press, 2000.

DERRIDA, J. Signature event context. Limited Inc. NorthwesternUniversity Press, p. 1-23, [1972] 1988. FABRÍCIO, B.F. A “outridade lusófona” em tempos de globalização: identidade cultural como potencial semiótico. In: MOITA LOPES, L.P. (Org). O português no século XXI: cenário geopolítico e sociolinguístico. São Paulo: Parábola, 2013. p. 144-168.

FOUCAULT, M. Os anormais. São Paulo: Martins Fontes, [2001]2010. 
FROSH, S.; PHOENIX, A; PATTMAN, R. Young masculinities: understanding Boys in contemporary society. New York: Palgrave, 2002.

GEE, J. Situated language and learning. A critique of traditional schooling. New York: Routledge, 2004. GIDDENS, A. As consequências da modernidade. São Paulo: Editora Unesp, 1991.

GOFFMAN, E. Footing. In: RIBEIRO, B. T.; GARCEZ, P. N. (Eds.). Sociolinguística interacional: antropologia, linguística e sociologia em análise do discurso. São Paulo: Loyola, [1979] 1998. p. 70-97.

HALL, S. A identidade cultural na pós-modernidade. Tradução de Tomaz Tadeu da Silva e Guacira Lopes Louro. 11. ed. Rio de Janeiro: DP\&A, 2006.

HENRIQUE, C. Reconstrução: uma abordagem sócio-histórica sobre o racismo à brasileira. Revista Urutágua. Maringá. Abr./Maio/Jun./Jul. 2007. Disponível em:

$<$ http://www.urutagua.uem.br/012/12henrique.pdf $>$.

HINE, C. Virtual ethnography. London: Sage Publications, 2000.

Virtual methods: issues in social research on the internet. Oxford: Berg Publishers, 2005.

HUTCHINSON, E.O. (1999). My gay problem, your black problem. In: CABADO, D.W. Black men on race, gender and sexuality. New York: New York University Press, p. 303-305, 1999.

ILARI, R.; GERALDI, J. W. Semântica. 11. ed. São Paulo: Ática, 2006.

LEVINSON, S.C. Pragmática. Trad. Luiz Carlos Borges; Aníbal Mari. São Paulo: Martins Fontes, 2007.

LIMA, A.; CERQUEIRA, F. A. Identidade homossexual e negra em alagoinhas. In: Bagoas estudos gays: gêneros e sexualidades, v. 1, n. 1, p. 269-286, 2007.

LOURO, G. Um corpo estranho. Belo Horizonte: Autêntica, 2004.

MELO, G.C.V.; MOITA LOPES, L.P. As performances discursivo-identitárias de mulheres negras em uma comunidade para negros na Orkut. DELTA, São Paulo, v. 29, p. 237-265, 2013.

A performance narrativa de uma blogueira: "tornando-se preta em um segundo nascimento". Alfa, Araraquara, v. 58, n. 3, p. 541-569, 2014.

MOITA LOPES, L.P. Identidades fragmentadas: a construção discursiva de raça, gênero e sexualidade em sala de aula. Campinas: Mercado de Letras, 2002.

Discursos sobre gays em uma sala de aula no Rio de Janeiro: é possível queer os contextos de letramento escolar? In: CONGRESSO LUSO-AFRO-BRASILEIRO DE CIÊNCIAS SOCIAIS - A questão social do novo milênio, 8., 2004, Coimbra. Anais do... Coimbra, 2004.

Por uma linguística aplicada interdisciplinar. SP: Parábola, 2006.

Os novos letramentos digitais como lugares de construção de ativismo político sobre sexualidade e gênero. Trab. Ling. Aplicada, Campinas, v. 49, n. 2, p. 393-417, 2010.

Em meio à multidão e seus desejos na web 2.0. In: SOUZA, E.M; LA GUARDIA, A; MARTINS, A.B. Figurações do íntimo. Belo Horizonte: Autêntica, 2013.

MUNANGA, K. Negritude usos e sentidos. São Paulo: Ática, 1986.

OCHS, E. Indexing gender in rethinking context: language as an interactive phenomenon. Ed. by A. Duranti \& C. Goodwin. Cambridge: Cambridge University Press, 1992. p. 335-358.

PARREIRAS, C. Fora do armário... dentro da tela: Notas sobre avatares, homossexualidades e erotismo a partir de uma comunidade virtual. In: DIAZ-BENITEZ, M.E.; FIGARD, C. E. Sexualidades dissidentes. Rio de Janeiro: Garamond, 2009.

PENNYCOOK, A. Uma linguística aplicada transgressiva. In: MOITA LOPES, L. P. (Org.). Por uma linguística aplicada interdisciplinar. São Paulo: Parábola, 2006. p. 67-84.

RAMPTON, B. Late modern language, interaction and schooling. In: RAMPTON, B. Language in late modernity: interaction in an urban school. Cambridge: Cambridge Press, 2006.

ROCHA, L. L. Teoria queer e a sala de aula de inglês na escola pública: performatividade, indexicalidade e estilização. 2013. Tese (Doutorado em Linguística Aplicada) - Programa Interdisciplinar de Linguística Aplicada, Universidade Federal do Rio de Janeiro, Rio de Janeiro, 2013.

RUTTER, J.; SMITH, G. Ethnografic presence in nebulous settings: a case study. In: Hine. C. Virtual methods: Issues in social research on the internet. Oxford: Berg Publishers, 2005. p. 81-92.

SEDGWICK, E.K. Epistemology of the closet. Londres: Penguin, 1990/2008.

MELO, Glenda Cristina Valim de; MOITA LOPES, Luiz Paulo da. Ordens de indexicalidade mobilizadas nas performances discursivas de um garoto de programa: ser negro e homoerótico. Linguagem em (Dis)curso LemD, Tubarão, SC, v. 14, n. 3, p. 653-673, set./dez. 2014. 
SILVA JUNIOR, P. M. A construção social das masculinidades no ambiente escolar: Uma visão de masculinidades possíveis nas periferias urbanas. Revista Científica Sensus: Pedagogia. n. 2, p. 47-59, jul./dez. 2011.

SIMÕES, J.A., FRANÇA, I.L., MACEDO, M. Jeitos de Corpo: Cor/raça, gênero, sexualidade e sociabilidade juvenil no centro de São Paulo. Cadernos Pagu, n. 35, p. 37-78, dez. 2010.

SILVERSTEIN, M. Indexical order and the dialectics of sociolinguistic life. Language \& Communication, 23, p.193-229, 2003.

Language and the culture of gender: At the intersection of structure, usage and ideology. In Elizabeth Mertz and Richard Parmentier (eds.) Semiotic Mediation: Sociocultural and Psychological Perspectives. New York: Academic Press, 1985. p. 219-259.

SOMMERVILLE, S. B. Queering the color line. Race and the inventions of homosexuality in america culture. Durham: Duke University, 2000.

SULLIVAN, N. Queer race. A critical introduction to queer theory. New York: New York University Press, 2003.

TANNEN, D. Conversational style: analyzing talk among friends. New York: Oxford University Press, [1984] 2005.

WILCHINS, R. Queer theory, gender theory: An instant primer. Los Angeles: Alyson Books, 2004.

WORTHAM, S. Narratives in action. NY: Teacher College Press, 2001.

\section{Recebido em: 19/11/13. Aprovado em: 24/09/14.}

Title: Indexicality orders mobilized in a hustler's discursive performances: Being black and gay

Authors: Glenda Cristina Valim de Melo; Luiz Paulo da Moita Lopes

Abstract: In this paper we analyze the orders of indexicality mobilized in Hiago's identity performance of race, gender and sexuality. We take into account Queer Theories and web theorizing as a space of coexistence of discourse and actors. This piece of research is based on virtual ethnography (HINE, 2000 e 2005) and data were generated in a chat between one of the researchers and Hiago. The analytical framework is based on Goffman's notion of footing and frame ([1979]1998) and on Blommaert's orders of indexicality (2006 e 2010).We observe that some specific orders of indexicality were mobilized by Hiago's multiple contradictory discursive performances.

Keywords: Race. Orders of indexicality. Discursive performances. Queer theory. Web.

Título: Órdenes de indexicalidad movilizadas en las performances discursivas de un acompañante masculino: ser negro y homoerótico

Autores: Glenda Cristina Valim de Melo; Luiz Paulo da Moita Lopes

Resumen: En este artículo analizamos las órdenes de indexicalidad movilizadas en las performances discursivas de raza, género y sexualidad de Hiago, un acompañante masculino. Para esto, nos basamos en las Teorías Queer y en teorizaciones sobre la web como un espacio de coexistencia de discursos y actores. Esta investigación tiene impresión etnográfico virtual (HINE, 2000 e 2005) y los datos fueron generados en un chat entre un de los Investigadores e Hiago. Como instrumento analítico nos basamos en las propuestas de Goffman ([1979]1998) de alineamiento y marco, y en la perspectiva de orden de indexicalidad Blommaert (2006 e 2010). Observamos que fueron movilizadas algunas órdenes de indexicalidad contradictorias en las múltiples performances discursivas de Hiago.

Palabras-clave: Raza. Órdenes de indexicalidad. Performances discursivas. Teorías Queer. Web. 